\title{
Respirando fundo: pressões e saúde na jornada do pesquisador
}

\section{Taking a deep breath: pressures and health in the researcher's journey}

\author{
Eneida Regina Fabian Holzmann ${ }^{1}$ \\ 0000-0003-0028-7120 \\ ${ }^{1}$ Pontifícia Universidade Católica de São Paulo, São Paulo, Brasil. ORCID: https://orcid.org/0000-0003-0028-7120
}

Autor para correspondência/Mail to: Eneida Regina Fabian Holzmann, eneida.holzmann@gmail.com

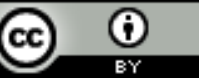

Copyright (c) 2021 Holzmann. Todo o conteúdo da Revista (incluindo-se instruções, política editorial e modelos) está sob uma licença Creative Commons Atribuição 4.0 Internacional. Ao serem publicados por esta Revista, os artigos são de livre uso em ambientes educacionais, de pesquisa e não comerciais, com atribuição de autoria obrigatória. Mais informações em http://revistas.ufpr.br/atoz/about/submissions\#copyrightNotice.

\section{Resumo}

Palestra proferida durante o Consórcio Mestral e Doutoral promovido pelo Programa de Pós-graduação em Gestão da Informação da Universidade Federal do Paraná em 2020.

\author{
Abstract \\ Lecture given during the Mestral and Doctoral Consortium promoted by the Postgraduate Program in Information Management at the Federal \\ University of Paraná in 2020.
}

Agradeço à coordenação do PPGGI o convite para participar deste consórcio mestral e doutoral. Eu gostaria de fazer uma reflexão com vocês sobre a jornada do pesquisador como um rito de passagem e por essa via lançar um novo olhar sobre o significado das pressões, do que pesa sobre nós nessa travessia, e sobre o que pode nos fortalecer para chegar até o final.

As passagens que vivenciamos como etapas sucessivas na nossa vida não são determinadas, como lembra a Profa. Dra. Carmen Junqueira, somente pela biologia (nascimento, infância, adolescência, fase adulta, madura, velhice e morte), mas traduzem mudanças de posição que se iniciam no sistema familiar, como, por exemplo, quando nos casamos e/ou quando passamos de filhos para pais, para formar um novo ramo da família. Essas passagens podem traduzir também uma busca por uma realização pessoal, acadêmica e profissional, implicando em uma mudança de posição no sistema familiar e social, de acordo com as nossas escolhas de vida.

As passagens são sempre marcadas por ritos. Os ritos de passagem se referem a uma sequência de ações, de práticas, que se realizam sempre da mesma forma e em ocasiões determinadas. Eles têm a função, desde o batismo, de agregar o indivíduo ao sistema a que ele pertence e gradativamente, de acordo com as escolhas, agregar o indivíduo a círculos de pertencimento cada vez mais amplos. Na infância, é marcante a entrada na escola; já o ingresso em grupos específicos, de música ou esportes, por exemplo, caracteriza a adolescência, até o enfrentamento do vestibular.

A graduação é um rito de passagem que exige um afastamento mais significativo do seio familiar, muitas vezes afastamento concreto com a mudança de cidade, ou mesmo de país, para a dedicação a um projeto maior. Todas essas passagens ou mudanças são acompanhadas por atos especiais, desde os mais simples, como o ato de raspar o cabelo quando da aprovação no vestibular, que, segundo a Profa. Dra. Carmen Junqueira, marca o rompimento dos vínculos com um estado anterior, até atos mais elaborados, como o da conquista do diploma, com a cerimônia da formatura.

A jornada do pesquisador no mestrado e no doutorado é um rito de passagem para o ingresso em uma comunidade acadêmica, rito que expressa uma mudança de status dentro dessa comunidade. A Profa. Dra. Freitas (2001), no seu livro Viva a tese! um guia de sobrevivência, fala do mestrado e doutorado como um rito de passagem que se traduz em uma grande conquista, a conquista da autonomia intelectual.

Os atos especiais que vivenciamos dentro dessa jornada, desde a apresentação e aprovação do projeto até a qualificação e defesa, refletem, segundo a mesma autora, o reconhecimento pela comunidade científica de que a mudança de uma situação para a outra é uma conquista importante, que deve ser buscada com persistência e desejada pelo pesquisador.

No livro Ritos de passagem da infância e adolescência, Junqueira (1985), a partir de um estudo realizado por Van Gennep em 1978, explica que um rito de passagem se inicia com um rito de separação, seguido de um rito de margem e um posterior rito de agregação, etapas que se repetiriam em todos esses processos de mudança, ao longo da vida. 
Desse modo, a jornada de cada um de nós, seja no mestrado ou no doutorado, implica em uma iniciativa de separação de uma cidade, da família, de um papel profissional, de rompimento de um equilíbrio, de um modo de viver. Ao entrarmos no programa, o rito de separação não é tão claramente marcado como quando passamos no vestibular, com o ato de raspar o cabelo, mas é sentido, à medida que exige abrir mão principalmente do convívio familiar e social de forma significativa, afastar-se, separar-se para poder se dedicar à pesquisa.

Com o início dos créditos, começa a etapa denominada rito de margem, como consequência da suspensão da vida comum ou das regras comuns familiares da nossa vida até então. Ao ingressarmos no programa, nos tornamos viajantes, estamos em uma cidade, um contexto, uma família ainda desconhecidos. Estamos à margem, observamos, fazemos os primeiros contatos, gradativamente nos expressamos, com as oportunidades e exigências das disciplinas, mas o fato é que sempre, de início, somos estranhos no ninho.

É mais fácil, mais comum durante a nossa vida, participarmos de ritos de separação elaborados, em situações de morte, de homenagens, e ritos de agregação, em ocasiões do nascimento e casamento. Na nossa realidade, da pós-graduação, o rito de margem também não é claramente marcado. No ciclo vital, poderia ser associado, por exemplo, à vivência da gestação. Uma gestante tem sua rotina, como cada um de nós, mas ao mesmo tempo está à margem, gerando uma nova vida. A Profa. Junqueira (1985) enfatiza que o rito de margem se refere a uma parada, um distanciamento, como se fosse um ponto morto entre as situações contrastantes de separação e agregação. Sua função seria de preparar a mudança, pois essencialmente se refere ao exercício de estarmos sós: somos nós e o nosso projeto de pesquisa.

Nessa etapa, ao iniciarmos a nossa jornada, além de estranhos no ninho, ou no programa, estamos sem a nossa pele e proteção anteriores e parecemos viver esquizofrenicamente. Estamos, sim, claramente em um movimento de expansão, fazendo contato com os professores e colegas, reconhecendo os espaços de laboratório, biblioteca, secretaria e, ao mesmo tempo, estamos grávidos de um projeto de pesquisa, com medo do futuro, enjoos, ganho de peso pela gradativa consciência da dimensão do desafio que decidimos encarar. E só nós estamos grávidos da nossa pergunta de pesquisa, com a responsabilidade de fazer crescer o texto até o parto, ou seja, até a qualificação.

Temos a expectativa e necessidade de aprender sobre o processo de pesquisa e da produção do texto. Essa é a essência do nosso desafio, e nós sabemos que é fundamental o envolvimento com o programa como um todo, que as disciplinas podem indicar caminhos, mas, ao mesmo tempo, internamente, estamos em processo de mudança, em uma nova família, e de novo (como quando crianças) em uma relação de dependência dos pais (ou do/da orientador/a ou do/da coorientador/a), dos irmãos mais velhos e mais novos (nossos colegas).

Olhando pela perspectiva de que é uma nova passagem e de que não é possível pular etapas, precisamos, para nos desenvolvermos, assim como quando éramos crianças, que os pais nos atribuam gradativamente responsabilidades, mas também que reconheçam e validem as nossas aquisições. Somos grandes por termos conquistado a vaga e a bolsa, e, ao mesmo tempo, no programa, no início, nos sentimos pequenos de novo. Muitas vezes temos receio de nos aproximar, fazer perguntas ao/à orientador/a com medo de um julgamento, achando que já deveríamos ter essas respostas. São fundamentais a aproximação e a abertura para o diálogo na nova família, porém o nosso principal alimento é a confiança de que o pai nos orientará e nos ensinará a caminhar com os próprios pés.

Eco (2012), em Como se faz uma tese, afirma que a relação com o/a orientador/a deve ser de mútua estima e confiança. Mesmo quando a graduação foi frustrante, a tese é uma oportunidade para recuperarmos o sentido positivo e progressivo do estudo e para a aquisição de novas competências. Além da exigência de adaptação a uma nova família, a vivência do cumprimento dos créditos tem se revelado, muito fortemente, como uma maratona que não permite tempo para a reflexão. O rito da margem, a necessidade de nos familiarizarmos, de nos prepararmos para o grande desafio de concluir uma obra, é sacudido por prazos e cobranças para a produção. Lidamos com a pressão relacionada ao aceite e/ou publicação de artigos e com a frustração por entregar textos muitas vezes incompletos, inacabados. A frustração também acontece, muitas vezes, pela percepção de termos sido desviados da rota.

É fundamental compreendermos a necessidade do programa, a exigência trazida pelo/pela orientador/a para a produção acadêmica, mas, na prática, conforme vivenciei e também ouvi de pesquisadores de diferentes áreas de estudo, é comum encontrarmos mestrandos e doutorandos em esgotamento, com insônia, ansiedade, além de sintomas físicos, pela luta contra o tempo. A depressão, no meu modo de entender, comumente alcança os pós-graduandos pela sensação de impotência diante de tantas demandas, pela ameaça de perda da bolsa e pelo isolamento ao realizarem atividades em pesquisas do laboratório, enquanto vivenciam um distanciamento do próprio projeto.

Na vivência da jornada do pesquisador como um grande ritual de passagem, é fundamental lembrarmos, nos valorizarmos pelo esforço inicial para a concepção do projeto de pesquisa, pelo esforço dedicado ao processo seletivo e pelo esforço para realizar e sustentar o rito da separação, do rompimento de vínculos com uma rotina anterior. No período que se segue é importante considerarmos que nem sempre nos é dado o tempo necessário para vivermos o rito da margem, tempo para nos familiarizarmos com a nova realidade, muito menos para cuidarmos do projeto que carregamos na barriga, ou melhor, no pensamento. Desse modo, cabe a nós respirar 
fundo, fluir com esse movimento de afastamento, e abrir um espaço na nossa vida para nos concentrarmos no processo de criação.

A saída do rito de margem é marcada pela qualificação do projeto. Na busca pela nossa autonomia intelectual, esse é o momento de maior pressão, no qual somos literalmente espremidos, questionados, e no qual o esforço é direcionado para encontrar a brecha pela qual poderemos prosseguir com o projeto de pesquisa já dentro da realidade. Com isso, recebemos o primeiro reconhecimento de paternidade e de pertencimento à nova família acadêmica e a permissão crucial do pai e da família para podermos ir adiante, para avançar e concluir a pesquisa.

A terceira etapa se caracteriza pelo rito de agregação, pela celebração da conquista, da mudança, que reúne a nova família acadêmica à mesa, que honra o viajante, o novo mestre, o novo doutor. Esse rito é vivenciado com a defesa final do projeto de pesquisa e representa uma vitória pessoal, da família, dos colegas, professores, do programa, da universidade e da sociedade como um todo.

Para nos fortalecer, é essencial observar que, dentro desse grande rito de passagem do mestrado, mais longo no doutorado, existem muitos ritos de passagem breves, aos quais podemos recorrer, com consciência e com a nossa persistência de viajantes. Assim, é muito importante perceber que, se estou excessivamente só, em um intervalo que parece querer se estender, posso me beneficiar com um rápido, mas profundo ritual de agregação: posso tomar um café na universidade com um colega, abrir um diálogo com um professor, ver a família. A consciência poderá promover um movimento de busca de equilíbrio, sempre na mesma sequência de etapas dos ritos de passagem, ou seja, de um momento de paralisação num rito de margem para um movimento de agregação. Ainda, na jornada nossa de pesquisadores pode haver a necessidade de novos ritos de separação relacionados ao trabalho, por exemplo, que facilitem novamente o movimento de afastamento, o retorno para o rito de margem, natural e necessário para o desenvolvimento da pesquisa.

Os ritos de passagem dizem respeito às mudanças contínuas enfrentadas por nós em nossa vida. Não podemos deixar de considerar que a repetição desses atos carrega, está impregnada de uma força, uma crença que se tornou uma verdade maior, compartilhada por muitas pessoas ao longo do tempo, ou seja, que se constituiu um mito. A Profa. Junqueira (1985) observa que nós, pesquisadores, estamos revivendo o mito da mudança: buscamos incessantemente as mudanças e acreditamos que a ciência é que transforma o mundo. No mestrado e no doutorado, estamos fazendo um esforço, um rito de passagem dentro de um grande esforço, anterior, de muitos outros que decidiram pela jornada do pesquisador.

Trazendo a reflexão para o contexto pessoal, vamos pensar que os nossos próprios atos estão impregnados por crenças. Nós também carregamos crenças que aprendemos na família, na escola, ou que trouxemos da própria graduação. Essas crenças podem estar expressas em frases, em ditados, em pensamentos, em imagens. As perguntas a seguir talvez possam ajudar a começarmos a nossa troca de ideias:

Quais são as crenças que eu carrego, as ideias preconcebidas que trago da família, da escola ou da graduação que podem estar gerando pressões para mim nesse momento, na minha jornada de pesquisador(a)?

Quais ações, diálogos e/ou movimentos que realizei só, ou com outra pessoa, me aliviaram dessas pressões? 


\section{REFERÊNCIAS}

Eco, H. (2012). Como se faz uma tese (24a. ed.). São Paulo: Perspectiva.

Freitas, M. E. d. (2001). Viva a teseum guia de sobrevivência. Rio de Janeiro: FGV.

Junqueira, C. (1985). Em trânsito: preparando a mudança. In Abramovich, f. ritos de passagem de nossa infância e adolescência: antologia (p. 175-180). São Paulo: Summus.

Como citar este artigo (APA):

Holzmann, E. R. F. (2021). Respirando fundo: pressões e saúde na jornada do pesquisador. AtoZ: novas práticas em informação e conhecimento, 10(2), 107 - 110. Recuperado de: http://dx.doi.org/10.5380/atoz.v10i2 .81221 